\title{
Selective Separation of Organic Electrolytes by Neutralization Dialysis with Grafted Polyethylene Films
}

\author{
Yuji Kimura, Kazunori Yamada* \\ Email address: \\ yamada.kazunori@nihon-u.ac.jp(K. Yamada) \\ ${ }^{*}$ Corresponding author
}

Department of Applied Molecular Chemistry, Nihon University, Narashino, Japan

\section{To cite this article:}

Yuji Kimura, Kazunori Yamada. Selective Separation of Organic Electrolytes by Neutralization Dialysis with Grafted Polyethylene Films. International Journal of Materials Science and Applications. Vol. 7, No. 3, 2018, pp. 95-105. doi: 10.11648/j.ijmsa.20180703.14

Received: November 14, 2017; Accepted: November 30, 2017; Published: April 26, 2018

\begin{abstract}
The selective separation of organic electrolytes by neutralization dialysis was investigated with two kinds of grafted polyethylene (PE) films prepared through the photografting of 2-(dimethylamino) ethyl methacrylate (DMAEMA) onto the PE films and the subsequent quaternization and through the photografting of glycidyl methacrylate (GMA) and the subsequent sulfonation. The permeation flux of benzoic acid (BA) for the quarternized DMAEMA-grafted PE (PE-g-QPDMAEMA) films increased with an increase in the degree of quaternization, and the BA permeability had the maximum at the initial $\mathrm{pH}$ value of the permeate solution of 12.0. On the other hand, the sulfonation offered the phenylalaninol (Phl) permeability of the GMA-grafted PE (PE-g-PGMA) films. The selective separation for the binary BA/Phl or 2,5-dichlorobenzoic acid/Phl systems was successfully achieved by use of a $\mathrm{pH}$ difference between the feed and permeate solutions through the PE-g-QPDMAEMA and sulfonated PE-g-PGMA (PE-g-SPGMA) films. The maximum selective separation was obtained under the conditions that the initial $\mathrm{pH}$ values of the permeate solutions through the PE-g-QPDMAEMA and PE-g-SPGMA films were adjusted to 12.0 and 2.0, respectively. This procedure will be applied to separation and concentration of organic electrolytes and water purification.
\end{abstract}

Keywords: Polyethylene, Photografting, 2-(dimethylamino) ethyl Methacrylate, Glycidyl Methacrylate, Neutralization Dialysis, Selective Separation

\section{Introduction}

A variety of synthesized polymer membranes are involved in membrane-separation processes, such as energy saving, resources recovery [1], and environmental preservation mainly for removal of metal or inorganic ions such as $\mathrm{K}^{+}, \mathrm{Ca}^{2+}$, $\mathrm{Mg}^{2+}, \mathrm{NO}^{3}$, and $\mathrm{SO}^{2}$ [2-4] and organic electrolytes [5-8] and for desalination [9-12]. Most of these membranes are highly crosslinked in order to increase their mechanical stability and avoid excessive water swelling. However, since the increased closslinking may cause a decrease in the membrane permeability of organic ions with relatively high molecular weights, either the degree of crosslinking or the chain length of the crosslinking agent used is frequently adjusted in improving the membrane permeability [13].

On the other hand, a graft copolymer consists of a long sequence of monomer referred to as a backbone with branches of a long sequence of another monomer. Therefore, compatibilization of a pair of polymers with quite different characteristics can be achieved without any crosslinking agents. Various grafted polyethylene (PE) films have been prepared by the photografting of hydrophilic, ionic, or reactive monomers and the resultant grafted PE films were applied to membrane-separation processes in previous articles [14-20]. One end of each grafted polymer chain is covalently bonded to the PE substrate and the other end is not placed under restraint. Therefore, the membrane properties and permeation behavior can successfully respond to the change in the external stimuli such as the $\mathrm{pH}$ value [14], temperature [14], and electric field [15]. In addition, positively or negatively ionizable functional groups successively affixed to the grafted polymer chains can work as a fixed carrier to transport ionic species across the grafted PE films [18]. Here, since PE is insoluble in water and most organic solvents at ambient temperatures, the PE films photografted with ionic monomers such as methacrylic acid or 
2-(dimethylamino) ethyl methacrylate (DMAEMA) possessed practical strength in the water-swollen state [14]. Negatively chargeable organic electrolytes were transported uphill by use of the $\mathrm{pH}$ difference [18] or through electrotransport [13] through the DMAEMA-grafted PE (PE-g-PDMAEMA) films.

We aimed at neutralization dialysis for the membrane separation of organic electrolytes. Neutralization dialysis has been mainly used for the selective separation of weakly acidic and basic compounds [21-23]. In this study, the application of the grafted PE films will be made to the selective separation of organic electrolytes through neutralization dialysis. The membranes for neutralization dialysis were prepared by the two-step process, or the photografting and functionalization. First, two different reactive functional monomers, DMAEMA and glycidyl methacrylate (GMA), were photografted onto the PE films [18-20]. Subsequently, functionalization of these grafted PE films, the quaternization of the PE-g-PDMAEMA films and sulfonation of GMA-grafted PE (PE-g-PGMA) films, was performed [24-28]. The permeability of the quaternized PE-g-PDMAEMA (PE-g-QPDMAEMA) and sulfonated PE-g-PGMA (PE-g-SPGMA) films to organic electrolytes was investigated by varying the initial $\mathrm{pH}$ value of the permeate solution, and then their selective permeation was estimated by use of the three-component type permeation cell.

\section{Experimental}

\subsection{Materials}

A PE film (thickness, $30 \mu \mathrm{m}$; density, $0.924 \mathrm{~g} / \mathrm{cm}^{3}$ ) was supplied from Tamapoly Co. Ltd., (Tokyo, Japan) and used as a polymeric substrate for photografting. The PE films of $6 \mathrm{~cm}$ in length and $3 \mathrm{~cm}$ in width were washed with methanol and acetone, and then dried under reduced pressure. DMAEMA and GMA were purchased from Tokyo Chemical Industry Co. (Tokyo, Japan) and used without further purification. All other reagents were analytical grade or higher.

\subsection{Photografting}

The photografting of DMAEMA and GMA onto the PE films was performed in the same manner described in previous articles [16-20]. An aqueous DMAEMA solution was prepared at $1.0 \mathrm{M}$ and the $\mathrm{pH}$ value was decreased to 8.0 with conc. $\mathrm{HCl}$ in order to increase the solubility of PDMAEMA $[18,19]$. A GMA monomer solution was prepared at $1.0 \mathrm{M}$ in an aqueous $80 \mathrm{vol} \%$ ethanol solution because the solubility of GMA is very low in water [20, 29]. The PE films were dipped in a $50 \mathrm{~cm}^{3}$ acetone solution containing $0.25 \mathrm{~g}$ benzophenone (BP) as a sensitizer, and then acetone was evaporated at room temperature to coat their surfaces with BP. DMAEMA and GMA were photografted onto the BP-coated PE films at $60^{\circ} \mathrm{C}$ by applying UV rays emitted from a $400 \mathrm{~W}$ high-pressure mercury lamp to the monomer solutions in which the PE films were immersed. The resultant PE-g-PDMAEMA and PE-g-PGMA films were washed with acetone for $24 \mathrm{~h}$ to remove homopolymers formed, and then dried under reduced pressure. The grafted amounts inmmol/g were calculated from the weight increases of the PE films after photografting using eq. (1):

$$
\text { Grafted amount }(\mathrm{mmol} / \mathrm{g})=\frac{\left(\mathrm{W}_{\mathrm{g}}-\mathrm{W}_{0}\right) / \mathrm{M}_{\mathrm{M}} \times 10^{3}}{\mathrm{~W}_{0}}
$$

where, Wg is the weight of a grafted PE film (g); W0, weight of an ungrafted PE film, andmM, $(\mathrm{g} / \mathrm{mol})$ molar mass of the monomer grafted (157.21 for DMAEMA and 142.15 for GMA).

\subsection{Functionalization of Grafted PE Film and Their Membrane Properties}

The quaternization of the PE-g-PDMAEMA films and sulfonation of the PE-g-PGMA films were performed as described below. The scheme of these reactions are illustrated in Figure 1. The PE-g-PDMAEMA films were immersed in dimethylsulfate ethanol solution at $60 \mathrm{wt} \%$ and the mixture was refluxed with moderate stirring for $3 \mathrm{hr}$ at $70^{\circ} \mathrm{C}$ [28].
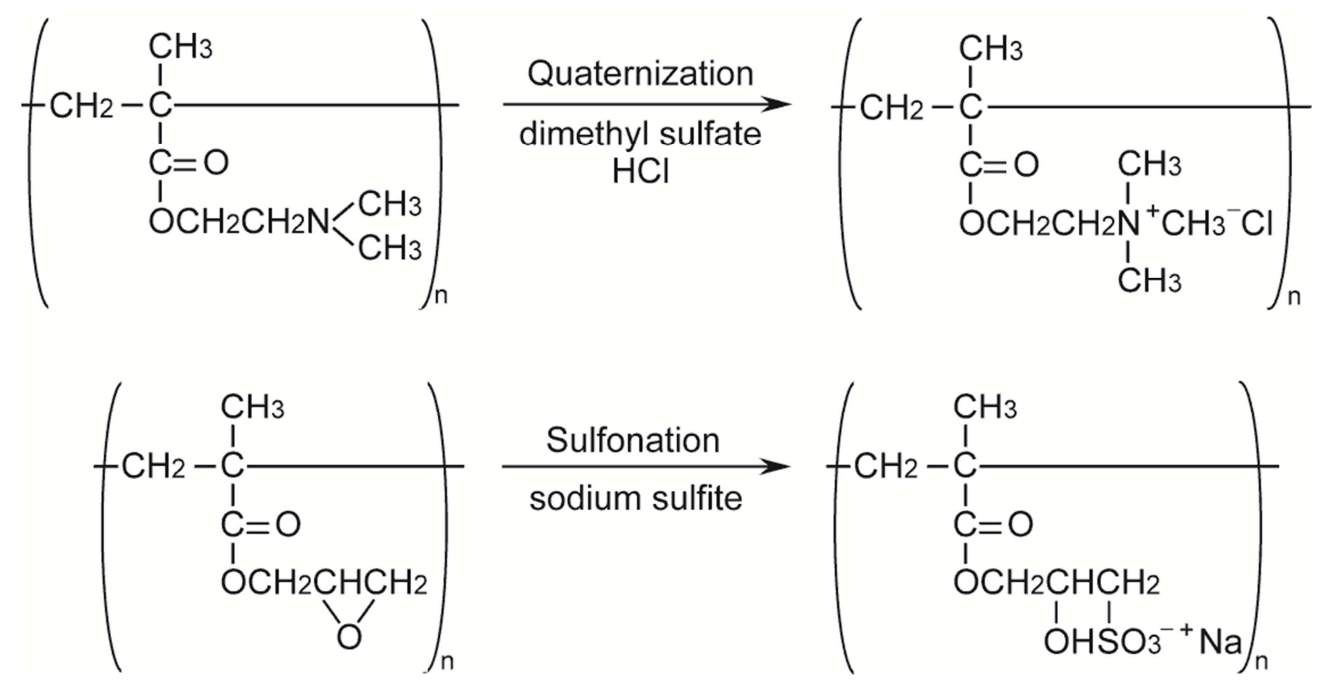

Figure 1. Functionalization of the PDMAEMA-g-PE and PGMA-g-PE films. 
After the reaction, the PE-g-QPDMAEMA films were washed with $1 \mathrm{M} \mathrm{HCl}$ and acetone. On the other hand, the PE-g-PGMA films were immersed in an aqueous solution containing sodium sulfate at $10 \mathrm{vol} \%$ and 2-propanol at 15 vol\%, and the reaction solution was heated at $70^{\circ} \mathrm{C}$ for $24 \mathrm{hr}$ with moderate stirring [30]. After the reaction, the PE-g-SPGMA films were washed with acetone. The degree of functionalization (quaternization and sulfonation) was calculated from the weight increase of the PE-g-PDMAEMA and PE-g-PGMA films after the reaction. The amount of absorbed water was calculated from the weight increase of the PE-g-QPDMAEMA and PE-g-SPGMA films immersed in distilled water for $24 \mathrm{hr}$ at $25^{\circ} \mathrm{C}$. In addition, the $n$ water value, the number of water molecules assigned per monomer segment, was calculated from the amounts of grafted amount and of adsorbed water using eq. (3) in ref. 14.

\subsection{XPS Analysis}

The XPS high-resolution spectra of carbon $\left(\mathrm{C}_{1 \mathrm{~s}}\right)$, oxygen $\left(\mathrm{O}_{1 \mathrm{~s}}\right)$, and sulfur $\left(\mathrm{S}_{2 \mathrm{p}}\right)$ of PE-g-PDMAEMA and PE-g-PGMA films before and after functionalization were recorded on a Shimadzu ESCA-3400 spectrophotometer (Kyoto, Japan) with $\operatorname{MgK} \alpha(1253.6 \mathrm{eV})$ source operating at $8 \mathrm{kV}$ and $20 \mathrm{~mA}$ [31-33].

\subsection{Permeation Control of Organic Electrolytes by the pH Difference}

The PE-g-QPDMAEMA or PE-g-SPGMA films swollen in water were fixed to the two-component type permeation cell $[15,18]$. First, the $\mathrm{pH}$ dependence of permeation of benzoic acid (BA, weak acid, $\mathrm{pKa}=4.2$ ) and benzenesulfonic acid (BSA, strong acid) was investigated for the PE-g-QPDMAEMA films. An aqueous solution of BA (initial $\mathrm{pH}=3.2$ ) or BSA (initial $\mathrm{pH}=2.1)$ at $10 \mathrm{mM}\left(100 \mathrm{~cm}^{3}\right)$ was put in one cell (feed side). An aqueous solution of $\mathrm{HCl}$ or $\mathrm{NaOH}$ at $\mathrm{pH} 2.0-12.0\left(100 \mathrm{~cm}^{3}\right)$ was put in the other side (permeate side). Both solutions were mildly stirred at $25^{\circ} \mathrm{C}$ and the $\mathrm{pH}$ values of both solutions and the amounts of permeated BA or BSA were measured at the prescribed time intervals. The aliquots of $0.5 \mathrm{~cm}^{3}$ were taken from the permeate solutions and diluted to $10 \mathrm{~cm}^{3}$ with an aqueous $\mathrm{HCl}$ solution of $\mathrm{pH} 2.0$.
The amounts of permeated BA and BSA were calculated from the absorbances at $229 \mathrm{~nm}$ for BA $\left(\log \varepsilon=4.006 \mathrm{dm}^{3} / \mathrm{mol} \cdot \mathrm{cm}\right)$ and $212.5 \mathrm{~nm}$ for BSA $\left(\log \varepsilon=4.141 \mathrm{dm}^{3} / \mathrm{mol} \cdot \mathrm{cm}\right)$, respectively. The permeation flux $\left(\mathrm{mmol} / \mathrm{cm}^{2} \cdot \mathrm{hr}\right)$ was calculated form the linear relationship of the permeated amounts, Qs, with the permeation time, $\Delta \mathrm{t}$, using eq (2)

$$
\text { permeation flux }\left(\mathrm{mmol} / \mathrm{cm}^{2} \cdot \mathrm{hr}\right)=\frac{\mathrm{Q}_{\mathrm{S}}}{\Delta \mathrm{t} \cdot 3.14}
$$

where the quantity of 3.14 is the effective membrane area $\left(\mathrm{cm}^{2}\right)$ [34].

Phenylalaninol $(\mathrm{Phl}, \mathrm{pKb}=6.2)$ as a weakly basic organic electrolyte was used for investigating the permeability of the PE-g-SPGMA films. The $\mathrm{pH}$ dependence of permeation of Phl was estimated by the above-mentioned procedure (log $\varepsilon$ $\left.=3.918 \mathrm{dm}^{3} / \mathrm{mol} \cdot \mathrm{cm}\right)$. In addition, the permeability of the PE-g-QPDMAEMA and PE-g-SPGMA films was measured as a function of the degree of functionalization and the grafted amount.

\subsection{Selective Separation of Organic Electrolytes}

The selective separation was investigated for the $\mathrm{BA} / \mathrm{Phl}$ and 2,5-dichlorobenzoic acid (diClBA, $\mathrm{pKa}=0.96$ ) $/ \mathrm{Phl}$ systems by use of the $\mathrm{pH}$ difference through the PE-g-QPDMAEMA and PE-g-SPGMA films. The PE-g-QPDMAEMA and PE-g-SPGMA films swollen in water were fixed with a three-component type permeation cell. An aqueous binary equimolar mixture solution of $\mathrm{BA} / \mathrm{Phl}$ or diClBA/Phl at $10 \mathrm{mM}$ was put in the central cell. An aqueous $\mathrm{NaOH}$ solution at $\mathrm{pH} 12.0$ was put in the permeation cell across a PE-g-QPDMAEMA film and an aqueous $\mathrm{HCl}$ solution at $\mathrm{pH} 2.0$ was put in the permeation cell across a PE-g-SPGMA film. Each solution was moderately stirred during the permeation experiments. The amounts of two organic electrolytes, designating one organic electrolyte as A and the other as B, permeated through the PE-g-QPDMAEMA and PE-g-SPGMA films from the binary feed solutions were determined by measuring the absorbances of the aliquots taken from the permeate solutions at two different wavelengths, $\lambda_{1}$ and $\lambda_{2}$, as shown in Figure 2.

\begin{tabular}{lccccc}
\hline \multicolumn{2}{c}{ binary component } & $\begin{array}{c}\lambda 1 \\
(\mathrm{~nm})\end{array}$ & $\begin{array}{c}\log \varepsilon 1 \\
\left(\mathrm{dm}^{3} / \mathrm{mol} \cdot \mathrm{cm}\right)\end{array}$ & $\begin{array}{c}\lambda_{2} \\
(\mathrm{~nm})\end{array}$ & $\begin{array}{c}\log \varepsilon 2 \\
\left(\mathrm{dm}^{3} / \mathrm{mol} \cdot \mathrm{cm}\right)\end{array}$ \\
\hline \multirow{2}{*}{$\mathrm{BA} / \mathrm{Phl}$} & $<\mathrm{BA}$ & 215.2 & 3.607 & 229.0 & 4.006 \\
& $\mathrm{Phl}$ & & 3.607 & & 1.929 \\
\multirow{2}{*}{$\mathrm{diClBA} / \mathrm{Phl}$} & $<\mathrm{diClBA}$ & 215.0 & 4.220 & & 3.995 \\
& & & & & \\
$\mathrm{Phl}$ & 225.0 & & 1.978 \\
\hline
\end{tabular}

Figure 2. Spectrophotometric determination of the permeated amounts for binary BA/Phl and diClBA/Phl mixture systems.

The absorbances, Abs1 and Abs2, were measured at one wavelength $\lambda 1$ at which the molar absorption coefficient of one organic electrolyte was the same as that of the other $\left(\varepsilon_{\mathrm{A} 1}\right.$ $\left.=\varepsilon_{\mathrm{B}_{1}}\right)$ and at the other wavelength $\lambda^{2}$ at which their molar absorption coefficients were quite different $\left(\varepsilon_{\mathrm{A}_{2}} \neq \varepsilon_{\mathrm{B}_{2}}\right)$. The amounts of permeated organic electrolytes were calculated using eqs. (3) and (4) [13, 35].

$$
\mathrm{Abs}_{2}=\mathrm{C}_{\mathrm{A}} \varepsilon_{\mathrm{A} 2} \mathrm{~L}+\mathrm{C}_{\mathrm{B}} \varepsilon_{\mathrm{B} 2} \mathrm{~L}=\mathrm{C}_{\mathrm{A}} \varepsilon_{\mathrm{A} 2} \mathrm{~L}+\left(\mathrm{C}_{\mathrm{A}+\mathrm{B}}-\mathrm{C}_{\mathrm{A}}\right) \varepsilon_{\mathrm{B} 2} \mathrm{~L}
$$




$$
\mathrm{Abs}_{1}=\mathrm{C}_{\mathrm{A}+\mathrm{B}} \varepsilon_{\mathrm{A} 1} \mathrm{~L}=\mathrm{C}_{\mathrm{A}} \varepsilon_{\mathrm{A} 2} \mathrm{~L}+\left(\mathrm{C}_{\mathrm{A}}+\mathrm{C}_{\mathrm{B}}\right) \varepsilon_{\mathrm{A} 1} \mathrm{~L}
$$

where $\mathrm{C}$ denotes the molar concentration of the organic electrolytes permeated, and $\mathrm{L}$ is the cell length $(1 \mathrm{~cm})$. In addition, separation factor was calculated using eq. (5):

$$
\text { separation factor }=\frac{Y_{A} / Y_{B}}{X_{A} / X_{B}}
$$

where $\mathrm{X}$ and $\mathrm{Y}$ denote the molar fraction of the organic electrolytes in the feed and permeate solutions, respectively [35].

The aliquots of $0.5 \mathrm{~cm}^{3}$ taken from the permeate solutions

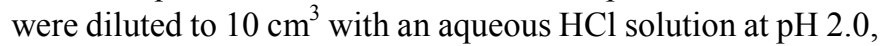
and the absorbances were measured at 215.2 and $229.0 \mathrm{~nm}$ for the binary $\mathrm{BA} / \mathrm{Phl}$ and $\mathrm{diClBA} / \mathrm{Phl}$ systems. The concentration of the organic electrolytes was measured in the same manner described above.

\section{Results and Discussion}

\subsection{Functionalization of PE-g-PDMAEMA and PE-g-PGMA Films}

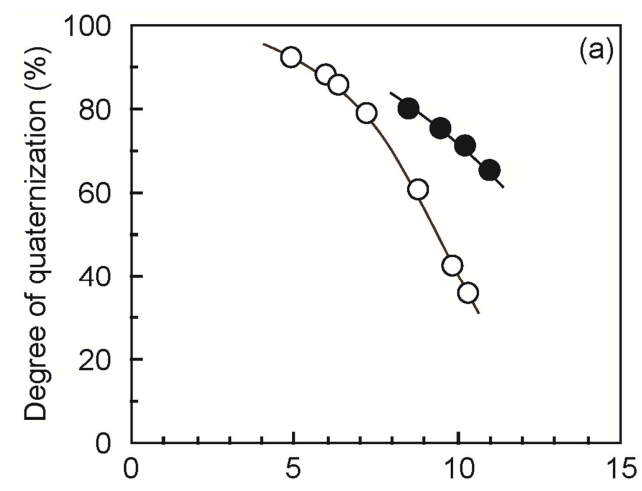

Amount of grafted DMAEMA $(\mathrm{mmol} / \mathrm{g})$

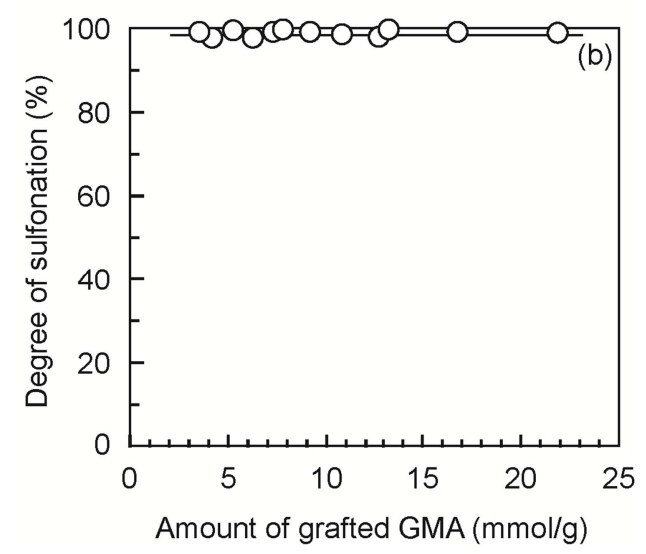

Figure 3. Changes in the degree of functionalization with the grafted amount for (a) the PE-g-PDMAEMA and (b) PE-g-PGMA films. (a) reaction time (hr)- ०: 3, •: 5. (b) sulfonation of the PE-g-PGMA films with sodium sulfite for $24 \mathrm{hr}$.
The PE-g-PDMAEMA films were quaternized with dimethylsulfate and the PE-g-PGMA films were sulfonated with sodium sulfate. Figure 3 shows the changes in (a) the degrees of quaternization for the PE-g-PDMAEMA films and (b) the degree of sulfonation for the PE-g-PGMA films with the grafted amount. The degree of quaternization decreased with an increase in the amount of grafted DMAEMA at the reaction time of $3 \mathrm{hr}$. Dimethylamino groups present in the inside of the PE-g-PDMAEMA films were not subject to the quaternization, although the PE-g-PDMAEMA films possessed a relatively high water absorptivity. Therefore, when the reaction time was prolonged to $5 \mathrm{hr}$ at grafted amounts higher than $8 \mathrm{mmol} / \mathrm{g}$, the degree of quaternization further increased and went up to $70 \%$ at $10 \mathrm{mmol} / \mathrm{g}$.

Here, the PE-g-PDMAEMA films can receive some damage at increased reaction times. In addition, since the photografting of DMAEMA progressed into the inside of the PE film at lower grafted amounts and the PE films were considerably expanded compared with the photografting of other hydrophilic monomers, such as methacrylic acid, acrylic acid, and methacrylamide, the PE-g-PDMAEMA films possessed higher water-absorptivity and a little lower strength in the water-swollen state than the other grafted PE films [14]. Therefore, the quaternization of PE-g-PDMAEMA films was carried out as brief a reaction time as possible. On the other hand, the degree of sulfonation of $97-100 \%$ was obtained irrespective of the grafted amount for the PE-g-PGMA films. Since PGMA was a water-insoluble polymer, the PE-g-PGMA had no solute permeability in the aqueous medium, sulfonation was considered to play an important role in conferring the water absorptivity and solute permeability to the PE-g-PGMA films.

\subsection{XPS Analysis of PE-g-QPDMAEMA and PE-g-SPGMA Films}

Figure 3 shows the typical XPS high-resolution spectra of $\mathrm{C}_{1 \mathrm{~s}}, \quad \mathrm{~N}_{1 \mathrm{~s}}, \mathrm{O}_{1 \mathrm{~s}}$, and $\mathrm{S}_{2 \mathrm{p}}$ for (a) PE-g-PDMAEMA, (b) PE-g-QPDMAEMA, (c) PE-PGMA, and (d) PE-g-SPGMA films. The XPS high-resolution $\mathrm{C}_{1 \mathrm{~s}}$ spectrum for the PE-g-PDMAEMA film showed a peak at $289 \mathrm{eV}$ assigned to - $\underline{C O O}-[31]$ and a peak at $288 \mathrm{eV}$ assigned to $-\underline{\mathrm{CH}} 2-\mathrm{N}\left(\mathrm{CH}_{3}\right)_{2}$ and $-\mathrm{N}(\underline{\mathrm{CH}} 3) 2$ groups in addition to a $\mathrm{N}_{1 \mathrm{~s}}$ peak at $400 \mathrm{eV}$. After the quaternization, a new peak assigned to a quaternized ammonium group appeared at $402 \mathrm{eV}$ in the $\mathrm{N}_{1 \mathrm{~s}}$ spectrum. On the other hand, for the PE-g-PGMA films, an overlapped peak at $288 \mathrm{eV}$ was enhanced and a new peak assigned to a sulfonate group appeared at $169 \mathrm{eV}$ in the high-resolution $\mathrm{S}_{2 \mathrm{p}}$ spectrum by the sulfonation. These results indicate that the functionalization, that is the quaternization for PE-g-PDMAEMA films and the sulfonation for PE-g-PGMA films, was successfully performed. 


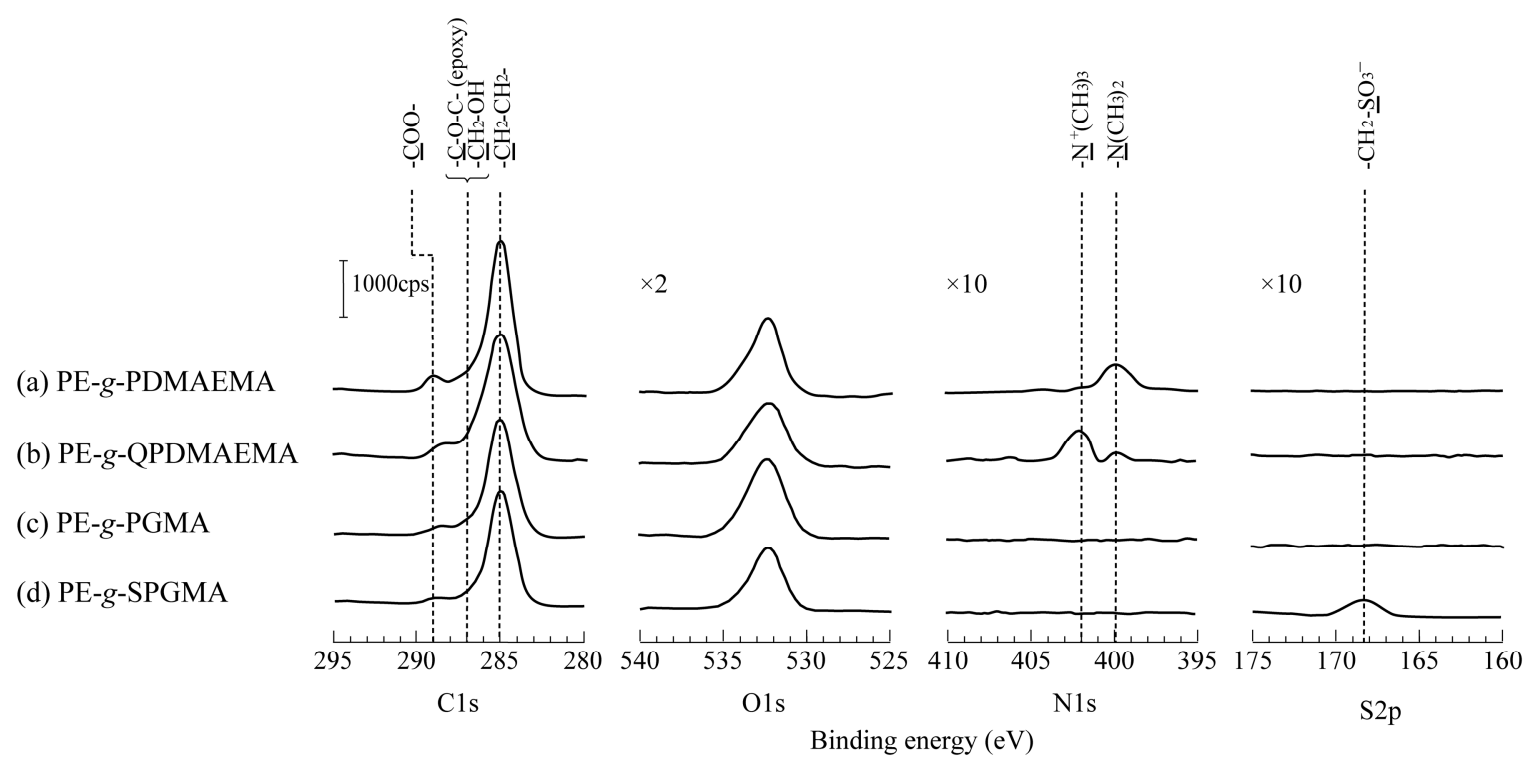

Figure 4. The C1s, Ols, N1s, and S2p core level spectra of (a) an PE-g-PDMAEMA film, (b) PE-g-QPDMAEMA film with the degree of quaternization $=84 \%$, (c) $P E-g-P G M A$ film, and (d) PE-g-SPGMA film with the degree of sulfonation $=100 \%$.

\subsection{Membrane Properties of PE-g-QPDMAEMA and PE-g-SPGMA Films}

The water-absorptivity of the PE-g-QPDMAEMA and PE-g-SPGMA films were estimated as a function of the degree of functionalization. Figure 5 shows the changes in the amount of absorbed water with the degree of functionalization for the PE-g-QPDMAEMA film with the grafted amount of $7.5 \mathrm{mmol} / \mathrm{g}$ and PE-g-SPGMA film with the grafted amount of $5.4 \mathrm{mmol} / \mathrm{g}$. The PE-g-PDMAEMA film possessed a relatively high water-absorptivity and an increase in quaternization led to a further increase in the water-absorptivity. Since the photografting of DMAEMA progresses in the inside of the PE films at lower grafted amounts, the PE film is subject to a little more expansion by water uptake [14]. On the other hand, sulfonation conferred the water absorptivity to the PE-g-PGMA films, which had little water absorptivity, and the amount of absorbed water linearly increased with an increase in the degree of sulfonation.

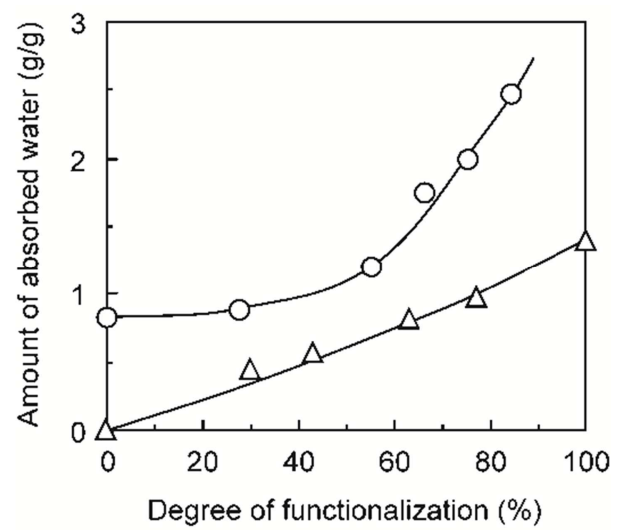

Figure 5. Changes in the amount of absorbed water with the degree of functionalization for the PE-g-QPDMAEMA with the grafted amount of $7.5 \mathrm{mmol} / \mathrm{g} \mathrm{(O)}$ and PE-g-SPGMA films with the grafted amount of $5.4 \mathrm{mmol} / \mathrm{g}$ ( $\Delta)$ films.

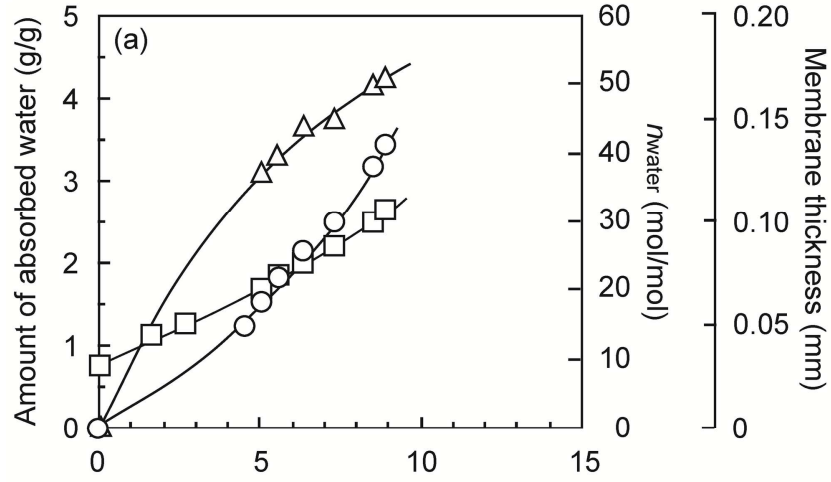

Amount of grafted DMAEMA $(\mathrm{mmol} / \mathrm{g})$

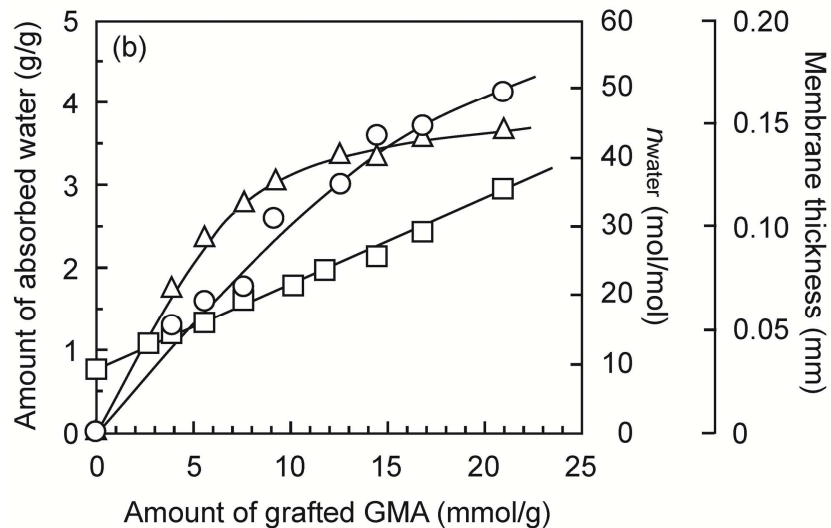

Figure 6. Changes in the amount of absorbed water (0), nwater value ( $\Delta)$, and thickness in the swollen state ( $\square$ ) with the grafted amount for the (a) PE-g-QPDMAEMA films with the degree of quaternization of $78-84 \%$ and (b) $P E-g-S P G M A$ films with the degree of sulfonation $=100 \%$ at $25^{\circ} \mathrm{C}$.

Figure 6 shows the changes in the amount of absorbed water, $n$ water value, and membrane thickness in the swollen state with the grafted amount for the PE-g-QPDMAEMA films with the degree of quaternization of $78-84 \%$ and the PE-g-SPGMA films with the degree of sulfonation of $100 \%$. 
The water-absorptivity for the PE-g-QPDMAEMA and PE-g-SPGMA films was higher than PE films grafted with other hydrophilic monomers [17]. The membrane thickness in the water-swollen state also increased with the grafted amounts due to water uptake. The PE films expanded not only due to the photografting of DMAEMA and GMA and but also due to water uptake by the subsequent functionalizations. The expansion of PE films indicates that the internal grafting occurs simultaneously with the surface grafting for the photografting of DMAEMA and GMA on the PE films [14, $17]$.

\subsection{Permeability of PE-g-QPDMAEMA Films}

The effects of the grafted amount, the degree of quaternization, and the initial $\mathrm{pH}$ values of the feed and permeate solutions on the BA and BSA permeation were investigated for PE-g-QPDMAEMA films. Figure 6 shows the variations in the permeation flux of $\mathrm{BA}$ and BSA with the grafted amount at the initial $\mathrm{pH}$ value of the permeate solution of 12.0 for the PE-g-QPDMAEMA films with the degree of quaternization of $78-84 \%$. The amounts of permeated BA and BSA linearly increased against the permeation time, while the $\mathrm{pH}$ values of the feed and permeate solutions remained almost unchanged. The permeation flux of BA and BSA obtained from the linear relationship of the permeated amounts against the permeation time had the maximum values at the grafted amount of $7.5 \mathrm{mmol} / \mathrm{g}$.

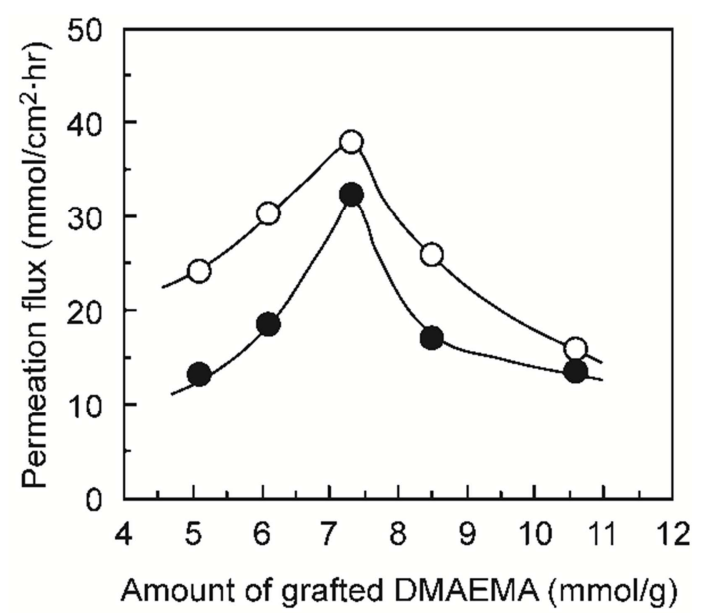

Figure 7. Variations in permeation flux of $B A$ (०) and BSA (•) with the grafted amount for the PE-g-QPDMAEMA films of the degree of quaternization of $78-84 \%$ at the initial $\mathrm{pH}$ value of the permeate solution of 12.0.

Here, no permeability of BA and BSA was observed at lower grafted amounts, since the ungrafted layer was left in the center of the PE film. The previous article reported that the ungrafted layer present the inside of the PE film disappeared at $5 \mathrm{mmol} / \mathrm{g}$ for the photografting of DMAEMA [17]. On the other hand, the permeability to BA and BSA sharply decreased at further increased grafted amounts. The PE films became hydrophilic by the photografting of DMAEMA onto the PE films and the subsequent quaternization of the PE-g-PDMAREMA films. Therefore, the water absorptivity increased over the degree of quaternization as shown in Figure 5. A further increase in the water absorptivity by these two kinds of modification procedures had a favorable effect on the increase in permeation of BA and BSA. In particular, the conversion of weakly chargeable dimethylamino groups in strongly chargeable trimethylammonium groups and the increase in the amount of trimethylammonium groups effectively led to the increase in the BA and BSA permeability as explained in the next section. Here, the net amount of strongly basic trimethylammonium groups increased with an increase in the amount of grafted DMAEMA under the conditions that the PE-g-QPDMAEMA films had a constant degree of quaternization of $78-84 \%$. It was found from a continuous increase in the nwater value as shown in Figure 6 that the water absorptivity increased over the grafted amount. However, the thickness of the PE-g-QPDMAEMA films also increased over the grafted amount in the water-swollen. Since the increase in the membrane thickness results in the increase in the membrane resistance, which would cause the decrease in the permeability of the PE-g-QPDMAEMA films. Since the permeation of $\mathrm{BA}$ and BSA through the PE-g-QPDMAEMA films decreased with an increase in the grafted amount in the range higher than $7.5 \mathrm{mmol} / \mathrm{g}$ as shown in Figure 7 , in this range the increase in the membrane thickness would be more highly influence on the membrane permeation than the increase in the water adsorptivity.

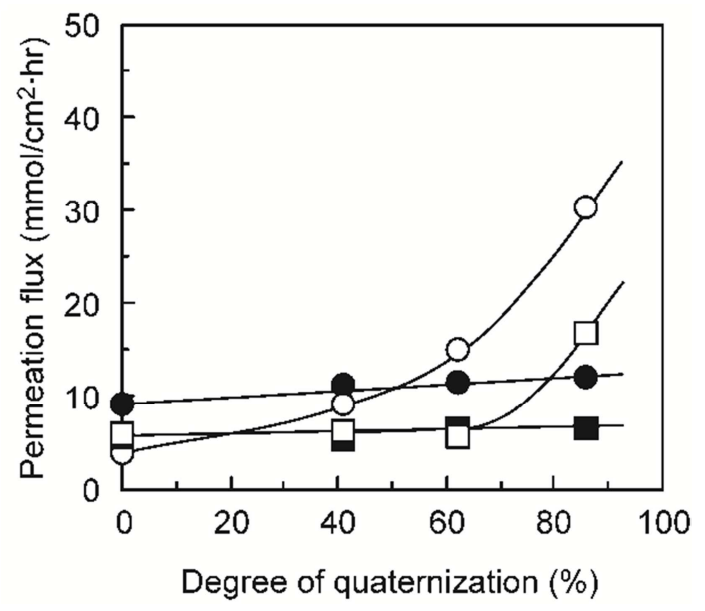

Figure 8. Changes in permeation flux of $B A(\circ, \bullet)$ and $B S A(\square, \mathbf{\square})$ with the degree of quaternization for the PE-g-QPDMAEMA films with the grafted amount of $6.0 \mathrm{mmol} / \mathrm{g}$ at the initial $\mathrm{pH}$ values of the permeate solution of 3.2 (shaded) and 12.0 (open).

Figure 8 shows the change in the permeation flux of BA and BSA with the degree of quaternization for PE-g-QPDMAEMA films with the grafted amount of $6.1 \mathrm{mmol} / \mathrm{g}$. The initial $\mathrm{pH}$ values of the permeate solutions were adjusted to either 3.2 corresponding to the $\mathrm{pH}$ value of an aqueous BA solution at $10 \mathrm{mM}$ or 12.0 . The permeation flux of BA and BSA was little independent of the degree of quaternization at the initial $\mathrm{pH}$ value of 3.2, and increased with an increase in the degree of quaternization at the initial $\mathrm{pH}$ value of 12.0 . Since a dimethylamino group is a weakly 
chargeable functional group, a PDMAEMA chain carries no positive charges at $\mathrm{pH} 12$ [18]. Therefore, the permeability to BA and BSA was low for PE-g-QPDMAEMA films with lower degrees of quaternization. On the other hand, BA and BSA anions can be ionically bonded to trimethylammonium groups affixed to the quaternized grafted PDMAEMA chains $\mathrm{BA}$ and BSA anions can be released from the PE-g-QPDMAEMA films due to ion-exchange with hydroxyl ions present in the permeate solution [28, 35]. These results indicate that ionically attractive interaction of BA or BSA anions with trimethylammonium groups affixed to the quaternized grafted PDMAEMA chains more successfully occurs due to an increase in the degree of quaternization.

Figure 9 shows the permeation flux of BA and BSA with the initial $\mathrm{pH}$ value of the permeate solution for a PE-g-QPDMAEMA film with the grafted amount of $6.2 \mathrm{mmol} / \mathrm{g}$ and the degree of quaternization of $86 \%$ and a PE-g-PDMAEMA film with the grafted amount of $6.2 \mathrm{mmol} / \mathrm{g}$. The BA and BSA permeabilities of the PE-g-QPDMAEMA and PE-g-PDMAEMA films were considerably low in the range of the initial $\mathrm{pH}$ values of 4.0 to 10.0 . In these cases, the $\mathrm{pH}$ values of each permeate solution sharply decreased from the initial $\mathrm{pH}$ values to about 4 and the $\mathrm{pH}$ difference between the feed and permeate solutions across the PE-g-QPDMAEMA or PE-g-PDMAEMA films decreased in a short time.
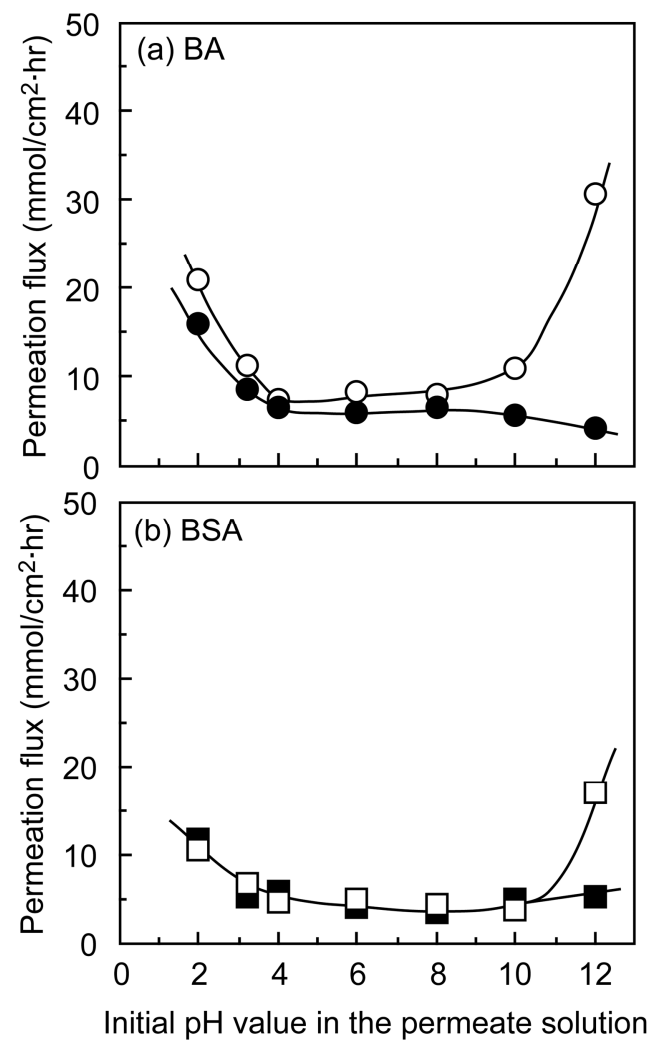

Figure 9. Variations in permeation flux of (a) $B A(\circ, \bullet)$ and (b) $B S A(\square, \mathbf{\square})$ with the initial $\mathrm{pH}$ value of the permeate solution for the PE-g-PDMAEMA film with the grafted amount of $6.1 \mathrm{mmol} / \mathrm{g}(\bullet, \mathbf{-})$ and PE-g-QPDMAEMA film with the grafted amount of $6.2 \mathrm{mmol} / \mathrm{g}$ and the degree of quaternization of $84 \%$ $(\circ, \square)$ films.
The PE-g-QPDMAEMA and PE-g-PDMAEMA films had relatively higher permeability to $\mathrm{BA}$ and $\mathrm{BSA}$ at the initial $\mathrm{pH}$ value of 2.0 than at the initial $\mathrm{pH}$ values of $4.0-10.0$. A PDMAEMA chain has little positive charges in the $\mathrm{pH}$ range higher than 10 as shown in Figure 1 in the ref. 13. Therefore, the grafted PDMAEMA chains were contracted at $\mathrm{pH} 12.0$, and the BA and BSA permeabilities of the PE-g-PDMAEMA film were lower than those of PE-g-QPDMAEMA films. On the other hand, more BA and BSA anions ionically complexed with trimethylammonium groups affixed to the grafted PDMAEMA chains and released into the permeate side through the ion exchange reaction with hydroxide ions at the interface facing to a permeate solution $[36,37]$. This behavior supports that the quaternization play a favorable role in the increase in the BA and BSA permeability. In addition, aqueous $\mathrm{HCl}$ solutions of $\mathrm{pH} 2.0$ containing $\mathrm{NaCl}$ of different concentrations were put in the permeate side, and the BA permeability was measured to discuss a high BA permeability of the PE-g-QPDMAEMA film at $\mathrm{pH}$ 2.0. The permeation flux of BA for the PE-g-QPDMAEMA film gradually increased with an increase in the $\mathrm{NaCl}$ concentration from 11 at $0 \mathrm{mM}$ to $17 \mathrm{mmol} / \mathrm{cm}^{2} \cdot \mathrm{hr}$ at $50 \mathrm{mM}$ (data not shown). The increase in the BA permeability is caused by contraction of quaternized grafted PDMAEMA chains. From this result, one of the reasons for the increase in the BA permeation at the initial $\mathrm{pH}$ value of 2.0 would be due to the screening effect by the addition of $\mathrm{HCl}$. In addition, the isometrical contraction of the PE-g-QPDMAEMA film fixed between the permeation cells will also lead to an increase in the BA permeability [27, 38]. It was found from the above experimental results that the PE-g-QPDMAEMA film had the maximum permeability to $\mathrm{BA}$ and $\mathrm{BSA}$ at the initial $\mathrm{pH}$ value of the permeate solution of 12.0.

\subsection{Permeability of PE-g-SPGMA Films}

The effects of the grafted amount, the degree of sulfonation, and the initial $\mathrm{pH}$ value of the permeate solution on the $\mathrm{Phl}$ permeation were investigated for the PE-g-SPGMA films. Figure 9 shows the variation in permeation flux of $\mathrm{Phl}$ with the grafted amount at the initial $\mathrm{pH}$ value of 2.0 for the PE-g-SPGMA films with the degree of sulfonation of $100 \%$. Here, since the ungrafted layer was left in the center of the PE film in the range of the grafted amounts lower than $4 \mathrm{~mol} / \mathrm{g}$, the PE-g-SPGMA films had no Phl permeability [22]. The Phl permeability increased with an increase in the amount of grafted GMA and had the maximum value at $6.2 \mathrm{mmol} / \mathrm{g}$. For PE-g-SPGMA films with a constant degree of sulfonation, the increase in the grafted amount leads to the net amount of sulfonic groups as well as the amount of absorbed water as shown in Figure 5, indicating that sulfonation has a favorable influence on the increase in the Phl permeability. However, since the thickness of the PE-g-PGMA films increased over the grafted amount by the photografting of GMA and subsequent sulfonation. The increase in the thickness had a positive influence on the Phl permeability of PE-g-SPGMA films as is the case with PE-g-QPDMAEMA films. Subsequently, the Phl permeability of the PE-g-SPGMA films 
on the degree of sulfonation was investigated at $6.2 \mathrm{mmol} / \mathrm{g}$.

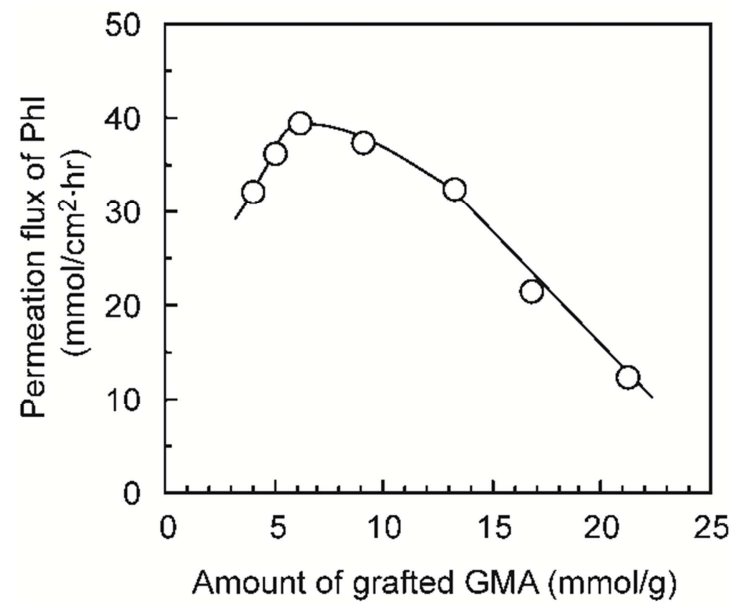

Figure 10. Variation in permeation flux of Phl with the grafted amount for the PE-g-SPGMA films with the degree of sulfonation of $100 \%$ at the initial $p H$ value of the permeate solution of 2.0.

Figure 10 shows the change in the permeation flux of $\mathrm{Phl}$ with the degree of sulfonation for the PE-g-SPGMA films with the grafted amount of $6.2 \mathrm{mmol} / \mathrm{g}$ at the initial $\mathrm{pH}$ value of the permeate solution of 2.0. No Phl permeation was observed through the PE-g-PGMA films because they had little water absorptivity. Since sulfonation offered hydrophilic properties to the PE-g-PGMA films, the Phl permeability increased with an increase in the sulfonation. In addition, the dependence of the $\mathrm{Phl}$ permeability on the initial $\mathrm{pH}$ value of the permeate solution was investigated for a PE-g-PSGMA film with the degree of sulfonation of $100 \%$.

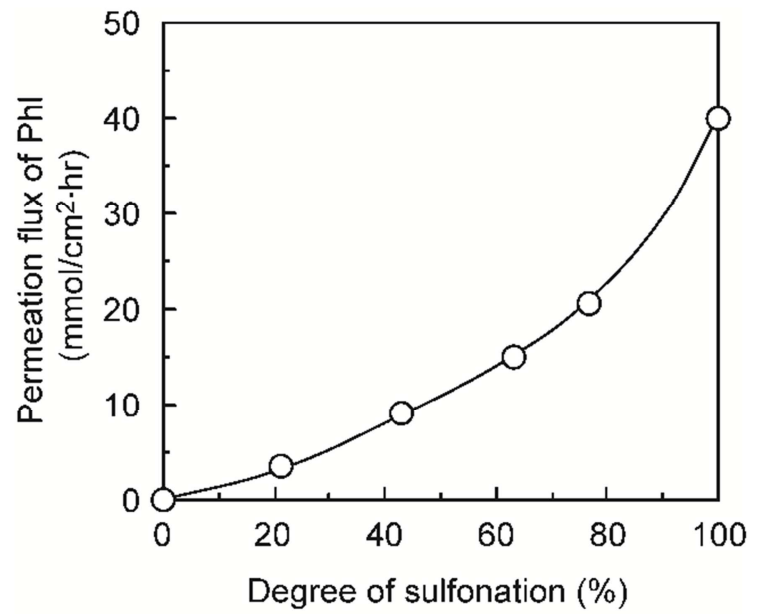

Figure 11. Change in permeation flux of Phl with the degree of sulfonation for the PE-g-SPGMA films with the grafted amount of $6.2 \mathrm{mmol} / \mathrm{g}$ at the initial $\mathrm{pH}$ values of the permeate solution of 2.0 .

Figure 12 shows the variation in permeation flux of $\mathrm{Phl}$ with the initial $\mathrm{pH}$ value of the permeate solution for the PE-g-SPGMA film. Since the $\mathrm{pH}$ value of the permeate solution sharply increased to reach about 8.5 in the initial $\mathrm{pH}$ range between 4.0 and 8.0 , the $\mathrm{Phl}$ permeability was considerably low. Here, the increase in the $\mathrm{pH}$ value of the permeate solution indicates that hydroxide ions sucessfully permeated through the PE-g-SPGMA films to the permeate solutions. The amount of permeated Phl gradually increased against the permeation time due to the concentration difference between the both solutions across the PE-g-SPGMA films at the initial $\mathrm{pH}$ values of 10.0 and 12.0. The PE-g-SPGMA film had a high permeability to $\mathrm{Phl}$ at the initial $\mathrm{pH}$ value of 2.0. Phl cations complexed with sulfonic groups appended to the sulfonated grafted PGMA chains are considered to be released into the permeate solution by the ionic exchange with hydrogen ions at the interface of the PE-g-SPGMA film. The maximum Phl permeability was obtained at the initial $\mathrm{pH}$ value of 2.0.

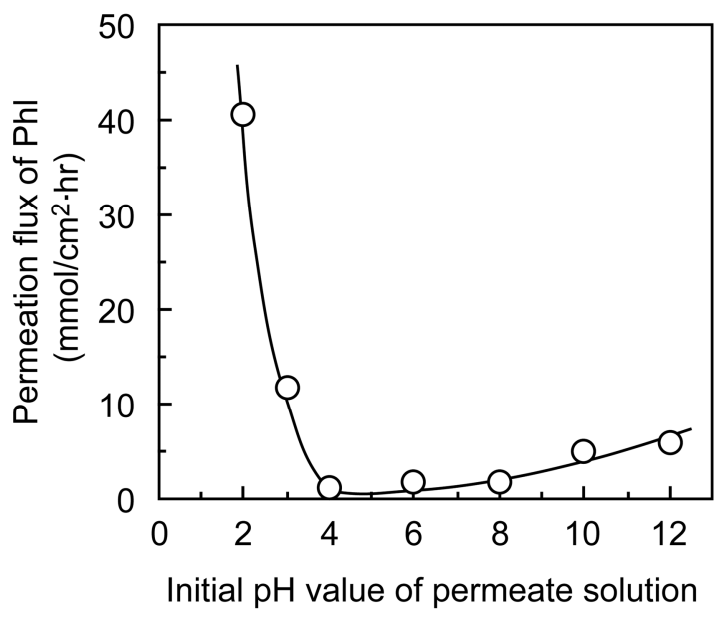

Figure 12. Variation in permeation flux of Phl with the initial $\mathrm{pH}$ value of the permeate solution for the PE-g-SPGMA films with the grafted amount of $6.2 \mathrm{mmol} / \mathrm{g}$ and the degree of sulfonation of $100 \%$.

\subsection{Selective Permeation of Organic Electrolytes}

On the basis of the above-mentioned results, the selective separation was investigated for the $\mathrm{BA} / \mathrm{Phl}$ system by using a PE-g-QPDMAEMA film with the grafted amount of $7.5 \mathrm{mmol} / \mathrm{g}$ and the degree of quaternization of $86 \%$ and a PE-g-SPGMA film with the grafted amount of $6.2 \mathrm{mmol} / \mathrm{g}$ and the degree of sulfonation of $100 \%$ in the three-component type permeation cell.

The $\mathrm{pH}$ values of the permeate solutions through the PE-g-QPDMAEMA and PE-g-SPGMA films were adjusted to 12.0 and 2.0, respectively. BA anions were selectively permeated through the PE-g-QPDMAEMA film. BA anions were complexed with trimethylammonium groups affixed to the quaternized grafted PDMAEMA chains, while Phl cations were repulsed against the quaternized grafted PDMAEMA chains. On the other hand, Phl cations were selectively permeated through the PE-g-SPGMA film because Phl cations were complexed with sulfonic groups affixed to the sulfonated grafted PGMA chains. Since it was found from these results that BA and Phl were selectively separated by use of the $\mathrm{pH}$ difference between the feed and permeate solutions through the PE-g-QPDMAEMA and PE-g-SPGMA films, the effect of the initial $\mathrm{pH}$ value of the $\mathrm{BA} / \mathrm{Phl}$ mixture solutions on their selective separation was investigated.

Figure 13 shows the effects of the initial $\mathrm{pH}$ value of the 
BA/Phl mixture solution on the separation factor. BA anions and $\mathrm{Phl}$ cations were selectively permeated through the PE-g-QPDMAEMA and PE-g-SPGMA films, respectively, irrespective of the initial $\mathrm{pH}$ value of the feed $\mathrm{BA} / \mathrm{Phl}$ mixture solution. The BA permeability of the PE-g-QPDMAEMA film and the Phl permeability of the PE-g-SPGMA film had maximum values at $\mathrm{pH} 6.45$ corresponding to the $\mathrm{pH}$ value of an equimolar $\mathrm{BA} / \mathrm{Phl}$ mixture solution without $\mathrm{pH}$ adjustment. Here, a decrease in the $\mathrm{pH}$ value of the $\mathrm{BA} / \mathrm{Phl}$ mixture solution restrained the dissociation of BA. On the other hand, an increase in the $\mathrm{pH}$ value results in the decrease in the protonation of $\mathrm{Phl}$. This behavior supports that as the initial $\mathrm{pH}$ value of the $\mathrm{BA} / \mathrm{Phl}$ mixture solution departs from $\mathrm{pH} 6.45$ by the addition of $\mathrm{HCl}$ or $\mathrm{NaOH}$, the neutralization between protons and hydroxide ions more preferentially occurs. Therefore, as the $\mathrm{pH}$ value of the $\mathrm{BA} / \mathrm{Phl}$ mixture solution departs from 6.45 , the selective separation between BA and $\mathrm{Phl}$ decreased. Next, the selective separation was investigated in the $\operatorname{diClBA} / \mathrm{Phl}$ system.

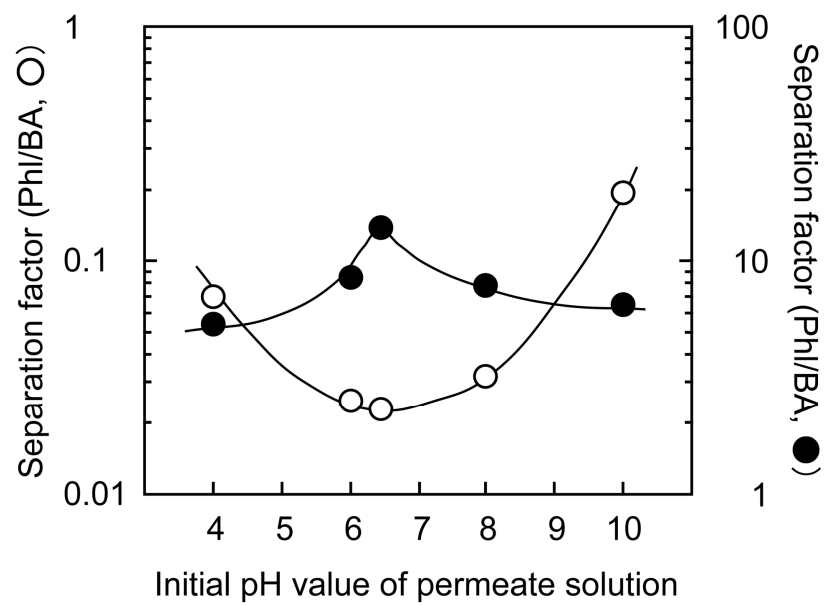

Figure 13. Effects of the initial $\mathrm{pH}$ value of the central feed side on the separation factors for the PE-g-QPDMAEMA film with the grafted amount of $7.5 \mathrm{mmol} / \mathrm{g}$ and the degree of quaternization of $86 \%$ (०) and PE-g-SPGMA film with the grafted amount of $6.2 \mathrm{mmol} / \mathrm{g}$ and the degree of sulfonation of $100 \%(\bullet)$ films in the binary Phl/BA systems. The $\mathrm{pH}$ values of the permeate solutions across the PE-g-QPDMAEMA and PE-g-SPGMA films were adjusted to be 12.0 and 2.0 , respectively.

Figure 14 shows the effects of the initial $\mathrm{pH}$ value of the diClBA/Phl mixture solution on the separation factors. diClBA anions and $\mathrm{Phl}$ cations were selectively permeated through the PE-g-QPDMAEMA and PE-g-SPGMA films, respectively, irrespective of the initial $\mathrm{pH}$ value of the feed mixture solution. The permselectivity for the $\mathrm{diClBA} / \mathrm{Phl}$ system had the maximum value at the initial $\mathrm{pH}$ value of 6.0 corresponding to the $\mathrm{pH}$ value of an equimolar $\operatorname{diClBA} / \mathrm{Phl}$ mixture solution without $\mathrm{pH}$ adjustment. As the initial $\mathrm{pH}$ value of the $\mathrm{diClBA} / \mathrm{Phl}$ mixture solution departed from 6.0, the permselectivity between the diClBA and $\mathrm{Phl}$ decreased. The addition of $\mathrm{HCl}$ or $\mathrm{NaOH}$ to the feed solution resulted in the decrease in the permselectivity for the diClBA/Phl system in the same manner as the $\mathrm{BA} / \mathrm{Phl}$ system. The separation factor had the mixture values at the initial $\mathrm{pH}$ values of 6.5 and 6.0 , which are the $\mathrm{pH}$ values of the equimolar $\mathrm{BA} / \mathrm{Phl}$ and
diClBA/Phl mixture solutions, respectively. The addition of $\mathrm{HCl}$ or $\mathrm{NaOH}$ for adjusting the $\mathrm{pH}$ values of the feed solutions increases in the concentration of coions $\mathrm{CH}^{+}$and $\mathrm{Cl}^{-}$ions for $\mathrm{HCl}$ and $\mathrm{Na}^{+}$and $\mathrm{OH}^{-}$for $\mathrm{NaOH}$ ). Therefore, as shown in Figures 12 and 13, the increase in the permeation of coions added in the feed solution through the PE-g-QPDMAEMA and PE-g-SPGMA films will suppress the permeation of organic ions.

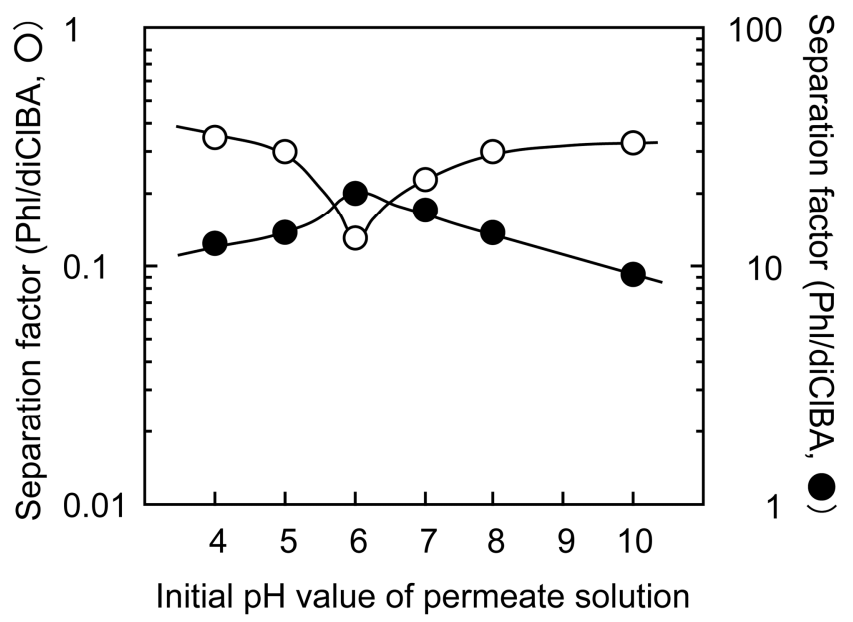

Figure 14. Effects of the initial $\mathrm{pH}$ value of the central feed side on the separation factors for the PE-g-QPDMAEMA film with the grafted amount of $7.5 \mathrm{mmol} / \mathrm{g}$ and the degree of quaternization of $86 \%$ (०) and PE-g-SPGMA film with the grafted amount of $6.2 \mathrm{mmol} / \mathrm{g}$ with the degree of sulfonation of $100 \%(\bullet)$ in the binary Phl/diClBA systems. The pH values of the permeate solutions across the PE-g-QPDMAEMA and PE-g-SPGMA films were adjusted to be 12.0 and 2.0, respectively.

\section{Conclusion}

In this study, the permeation control and selective separation of organic electrolytes by use of the $\mathrm{pH}$ difference with the PE-g-QPDMAEMA and PE-g-SPGMA films were investigated and the following conclusions was obtained. The permeation flux of BA for the PE-g-QPDMAEMA film increased with an increase in the degree of quaternization, and the PE-g-QPDMAEMA film with the grafted amount of $7.5 \mathrm{mmol} / \mathrm{g}$ had the maximum BA permeability at the initial $\mathrm{pH}$ value of the permeate solution of 12.0. In addition, the sulfonation offered the permeation of Phl to the pPE-g-PGMA films, and the PE-g-SPGMA film had the maximum Phl permeability at $6.2 \mathrm{mmol} / \mathrm{g}$.

The selective separation for the binary $\mathrm{BA} / \mathrm{Phl}$ and diClBA/Phl systems was achieved by use of the $\mathrm{pH}$ difference between the feed and permeate solutions through the PE-g-QPDMAEMA and PE-g-SPGMA films. The maximum permselectivity was obtained for the binary $\mathrm{BA} / \mathrm{Phl}$ and diClBA/Phl systems under the experimental conditions that the initial $\mathrm{pH}$ values of the feed solutions through the PE-g-QPDMAEMA film and PE-g-SPGMA film were adjusted to 12.0 and 2.0 , respectively and the equimolar organic electrolyte mixture solutions were put in the central feed without any $\mathrm{pH}$ adjustment. The above-mentioned results indicate that acidic and basic organic electrolytes are 
selectively separated by use of the $\mathrm{pH}$ difference through the PE-g-QPDMAEMA and PE-g-SPGMA films by neutralization dialysis technique. This procedure will be applied to separation and concentration of organic electrolytes and water purification.

\section{References}

[1] G. A. Denisov, G. A. Tishchenko, M. Bleha, L. K. Shataeva, "Theoretical analysis of neutralization dialysis in the three-component membrane cell," J. Memb. Sci., Vol. 98, No. 1-2, pp. 13-25, 1995.

[2] A. Elmidaoui, S. Belcadi, Y. Houdus, T. Cohen, C. Gavach, "Perfluorinated anion-exchange membranes- preparation and preliminary tests dialysis," J. Polym. Sci., A: Polym. Chem., Vol. 30. No. 7, pp. 1407-1412, 1992.

[3] T. Sata, T. Yamaguchi, K. Matsusaki, "Effect of hydrophobicity of ion-exchange groups of amion-exchange membranes of permselectivity between 2 anions," J. Phys. Chem., Vol. 99, No. 34, pp. 12875-12882, 1995.

[4] T. Sata, K. Teshima, K. Yamaguchi, "Permselectivity between two anions in anion exchange membranes crosslinked with various diamines in electrodialysis" J. Polym. Sci., A: Polym. Chem., Vol. 34, No. 8, pp. 1475-1482, 1996.

[5] Y. Zhang, L. Pinoy, B. Meesschaert, B. Van der Bruggen, "Separation of small organic ions from salts by ion-exchange membrane in electrodialysis," AIChE J. Vol. 57, No. 8, pp. 2070-2078, 2011.

[6] S. Zeidler, U. Kätzel, P. Kreis, "Systematic investigation on the influence of solutes on the separation behavior of a PDMS membrane in organic solvent nanofiltration," J. Memb. Sci., Vol. 429, No. 15, pp. 295-303, 2013.

[7] E. Fontananova, G. Di Profio, F. Artusa, E. Drioli, "Polymeric homogeneous composite membranes for separations in organic solvents," J. Appl. Polym. Sci., Vol. 129, No. 4, pp. 1653-1659, 2013.

[8] G. Wang, H. Tababe, M. Igawa, "Transport of glycine by neutralization dialysis," J. Memb. Sci., Vol. 106, No. 3, pp. 207-211, 1995.

[9] M. Igawa, K. Mikawa, H. Okachi, "Transport characteristics of neutralization dialysis and desalination of tap water," Bull. Chem. Soc. Jpn., Vol. 76, No. 2, pp. 437-441, 2003.

[10] M. Chérif, I. Mkacher, R. Ghalloussi, L. Chaabane, A. Ben Salah, K. Walha, "Experimental investigation of neutralization dialysis in three-compartment membrane stack," Desalin. Water Treat., Vol. 56, No. 10, pp. 9363-9370, 2015.

[11] M. Chérif, I. Mkacher, L. Dammak, A. Ben Salah, K. Walha, D. Grande, V. Nikonenko, "Water desalination by neutralization dialysis with ion-exchange membranes: Flow rate and acid/alkali concentration effects," Desalination, Vol. 361, No. 1, pp. 13-24, 2015.

[12] M. Chérif, I. Mkacher, L. Dammak, A. Ben Salah, K. Walha, V. Nikonenko, "Fractional factorial design of water desalination by neutralization dialysis process: concentration, flow rate, and volume effects," Desalin. Water Treat., Vol. 57, No. 31, pp. 14403-14413, 2016.
[13] K. Yamada, T. Taki, K. Sato, M. Hirata, "Electrotransport of organic electrolytes through 2-(dimethylamino) ethyl methacrylate-grafted polyethylene films and their separation and concentration," J. Appl. Polym. Sci., Vol. 89, No. 9, pp. 2535-2344, 2003.

[14] K. Yamada, K. Sato. S. Tatekawa, M. Hirata, "Membrane properties of polyethylene films photografted with hydrophilic monomers," Polym. Gels Networks, Vol. 2, No. 3-4, pp. 323-331, 1994.

[15] K. Yamada, K. Sasaki, M. Hirata, "Separation and concentration of anionic organic electrolytes by electrotransport through polyethylene films grafted cationic polymers," in Field Responsive Polymers. Electroresponsive, Photoresponsive, and Responsive Polymers in Chemistry and Biology, ACS Symposium Series 726; American Chemical Society: Washington, DC, Chapter 21, pp. 16-24, 1999.

[16] T. Taki, K. Yamada, M. Hirata, "Concentration of organic electrolytes by electrotransport using polyethylene films photografted with ionic monomers," Trans. Mater. Res. Soc. Jpn., Vol. 24, No. 4, pp. 553-548, 1999.

[17] K. Yamada, S. Tatekawa, M. Hirata, "Polyethylene film gels prepared by photografting of hydrophilic monomers," $J$. Colloid Interface Sci., Vol. 162, No. 1, pp. 144-150, 1994.

[18] K. Yamada, K. Sato, M. Hirata, "Uphill transport of organic electrolytes using polyethylene films photografted with 2-(dimethylamino) ethyl methacrylate," J. Mater. Sci., Vol. 34, No. 5, pp. 1081-1091, 1999.

[19] K. Yamada, M. Shibuya, C. Takagi, M. Hirata, "Adsorption and desorption properties of cationic polyethylene film gels to organic anions and their regeneration," J. Appl. Polym. Sci., Vol. 99, No. 1, pp. 381-391, 2006.

[20] K. Yamada, R. Nagano, M. Hirata, “Adsorption and desorption properties of the chelating membranes prepared from the PE films," J. Appl. Polym. Sci., Vol. 99, No. 4, pp. 1895-1902, 2006.

[21] H. Tanabe, H. Okachi, M. Igawa, "Separation of weak acids and bases by neutralization dialysis," Ind. Eng. Chem. Res., Vol. 34, No. 7, pp. 2450-2454, 1995.

[22] M. Bleha, G. A. Tishchenko, "Neutralization Dialysis for Desalination," J. Memb. Sci., Vol. 73, No. 2-3, pp. 305-311, 1992.

[23] M. Igawa, H. Tanabe, T. Ida, F. Yamamoto, H. Okachi, "Separation of weak acids and bases by neutralization dialysis," Chem. Lett., No. 9, pp. 1591-1594, 1993.

[24] Y. Takeuchi, K. Fujita, N. Tsubokawa, "Preparation of amphiphilic carbon black by postgrafting of polyethyleneimine to grafted polymer chains on the surface," Polym. Bull., Vol. 41, No. 1, pp. 85-90, 1998.

[25] R. R. Navarro, K. Sumi, M. Matsumura, "Improved metal affinity of chelating adsorbents through graft polymerization," Water Res., Vol. 33, No. 9, pp. 2037-2044, 1999.

[26] R. R. Navarro, K. Tatsumi, K. Sumi, M. Matsumura, "Role of anions on heavy metal sorption of a cellulose modified with poly (glycidyl methacrylate) and polyethyleneimine," Water Res., Vol. 35, No. 11, pp. 2724-2730, 2001. 
[27] R. Molinari, P. Argurio, T. Poerio, "Comparison of polyethylenimine, polyacrylic acid and poly (dimethylamine-co-epichlorohydrin-co-ethylenediamine) in $\mathrm{Cu}^{2+}$ removal from wastewaters by polymer-assisted ultrafiltration," Desalination, Vol. 162, No. 1-3, pp. 217-228, 2004.

[28] S. M. Gawish, A. Kantouch, A. M. El Naggar, S. Mosleh, "Grafting of 2-(dimethylamino) ethyl-methacrylate onto gamma-irradiated polypropylene fablic," J. Appl. Poylm. Sci., Vol. 44, No. 9, pp. 1671-1677, 1992.

[29] K. Yamada, Y. Saitoh, Y. Haga, K. Matsuda, M. Hirata, "Adsorption and desorption properties of grafted polyethylene films modified with polyethylenimine chains," J. Appl. Poylm. Sci., Vol. 102, No. 6, pp. 5965-5976, 2006.

[30] D. Okamura, K. Saito, K. Sugita, M. Tamada, T. Sugo, "Effect of alcohol solvents for glycidyl methacrylate in radiation-induced graft polymerization on performance of cation-exchange porous membranes, Membrane, Vol. 27, No. 4, pp. 196-201, 2002 (in Japanese).

[31] K. Yamada, J. Kimura, M. Hirata, "Surface Modification and Autohesive Properties of Poly (tetrafluoroethylene) and Polyethylene by the Photografting Technique," J. Photopolym. Sci. Technol., Vol. 11, No. 2, pp. 263-270, 1998.

[32] S. S. Mikhailova, O. M. Mykhaylyk, A. M. Dorfman, V. I. Povstugar, "XPS study of finely dispersed iron powders modified by radiation-grafted acrylamide," Sur. Interface Anal., Vol. 29, No. 8, pp. 519-523, 2000.
[33] A. Khot, A. Bailey, T. Debies, G. A. Takacs, "XPS studies of poly (acrylic acid) grafted onto UV photo-oxidized polystyrene surfaces," J. Adhes. Sci. Technol., Vol. 26, No. 23, pp. 2627-2639, 2012.

[34] K. Yamada, T. Gondo, M. Hirata, "Application of DMAEMA-grafted expanded PTFE films to positively charged ultrafiltration membranes and their electrostatic sieve separation properties," J. Appl. Poylm. Sci., Vol. 81, No. 7, pp. 1595.-1604, 2001.

[35] V. I. Vasil'eva, E. A. Goleva, "Selective separation of sodium ions from a mixture with phenylalanine by Donnan dialysis with a profiled sulfogroup cation exchange membrane," Russ. $J$. Phys. Chem., Vol. 90, No. 10, pp. 2035-2043, 2016.

[36] M. German, A. K. DenGupta, J. Greenleaf, “Hydrogen Ion $\left(\mathrm{H}^{+}\right)$ in waste acid as a driver for environmentally sustainable processes: Opportunities and challenges," Environ. Sci. Technol., Vol. 47, No. 5, pp. 2145-2150, 2013.

[37] S. Tsukahara, B. Nanzai, M. Igawa, "Selective transport of amino acids across a double membrane system composed of a cation- and an anion-exchange membrane," J. Memb. Sci., Vol. 448, pp. 300-307, 2013.

[38] Y. Osada, Y. Takeuchi, "Water and protein permeation through polymeric membrane having mechanochemically expanding and contracting pores. Function of chemical valve. I," J. Polym. Sci., Polym. Lett., Vol. 19, No. 6, pp. 303-308, 1981. 